\title{
The surface electromyography analysis of the non-plegic upper limb of hemiplegic subjects
}

\author{
Heloyse U. Kuriki ${ }^{1,2}$, Raquel N. de Azevedo', Augusto C. de Carvalho', \\ Fábio Mícolis de Azevedo', Rúben F. Negrão-Filho' ${ }^{1}$, Neri Alves ${ }^{1,2}$
}

\begin{abstract}
Many authors have studied physical and functional changes in individuals post-stroke, but there are few studies that assess changes in the non-plegic side of hemiplegic subjects. This study aimed to compare the electromyographic activity in the forearm muscles of spastic patients and clinically healthy individuals, to determine if there is difference between the non-plegic side of hemiplegics and the dominant member of normal individuals. 22 hemiplegic subjects and 15 clinically healthy subjects were submitted to electromyography of the flexor and extensor carpi ulnaris muscles during wrist flexion and extension. The flexor muscles activation of stroke group (average 464.6 u.n) was significantly higher than the same muscles in control group (mean: 106.3 u.n.) during the wrist flexion, what shows that the non affected side does not present activation in the standart of normality found in the control group.
\end{abstract}

Key words: muscle spasticity, surface electromyography, hemiplegia.

\section{Análise da eletromiografia de superfície do membro superior não plégico de hemiplégicos}

\section{RESUMO}

Muitos autores estudaram as modificações funcionais e físicas em indivíduos pós-acidente vascular cerebral; porém, poucos estudos avaliam alterações no hemicorpo não plégico de indivíduos hemiplégicos. O objetivo deste estudo foi comparar a atividade eletromiográfica nos músculos do antebraço de pacientes espásticos e indivíduos clinicamente saudáveis, para averiguar se há diferença entre o lado não plégico de indivíduos hemiplégicos e o lado dominante de indivíduos clinicamente saudáveis. 22 indivíduos hemiplégicos e 15 clinicamente saudáveis foram submetidos à eletromiografia dos músculos flexor e extensor ulnar do carpo durante a flexão e extensão do punho. A ativação dos músculos flexores dos hemiplégicos (média: 464,6 u.n), foi significantemente maior que nos indivíduos do grupo controle (média: 106,3 u.n) durante o movimento de flexão do punho, o que demonstra que o hemicorpo não acometido dos pacientes estudados não apresenta o comportamento padrão de normalidade encontrado no grupo controle.

Palavras-chave: espasticidade muscular, eletromiografia de superfície, hemiplegia.

\section{Correspondence}

Heloyse Uliam Kuriki

Laboratório de Fisioterapia Aplicada

ao Movimento Humano

Departamento de Fisioterapia

Rua Roberto Simonsen 305

19060-900 Presidente Prudente SP - Brasil

E-mail: heloysekuriki@yahoo.com.br

\section{Support}

Bolsa de Pesquisa FAPESP/ IC

(proc. N. 06/51155-0)

Received 28 October 2009

Received in final form 4 January 2010

Accepted 14 January 2010
After a stroke, a lot of hemiplegic patients are able to walk during early rehabilitation, but most of them are unable to use their upper extremities in their activities of daily living (ADL), after months of standard occupational therapy and physiotherapy. It was estimated that $55 \%$ of stroke survivors have a non-functional upper extremity after initial therapy and that $30 \%$ of hemiplegics had some partial recovery of upper extremity function in terms of range of motion and strength, but are still unable to perform the daily activities with the affected limbs. It occurs because the motor 
recovery of upper limb of hemiplegics is known to occur mainly in the proximal upper limb (shoulder and elbow), but is always limited in the distal (wrist) ${ }^{1,2}$. These facts indicate the need for more studies in order to understand changes found in the upper limbs of hemiplegics, as well as therapeutic approach aimed at them ${ }^{3}$.

It is known that the lesion in the motor cortex or corticospinal tract, as occurs in a stroke, can result in loss of movement on the contralateral side of the body, ranging from a transient weakness, decreased accuracy and strength or a complete and lasting paralysis, depending on the kind and extent of the injury. However, there is a growing trend that these losses are not only contralateral but also ipsilateral ${ }^{4}$. Perhaps these losses are related to the mode of division and crossing of the cortico-spinal fibers that are responsible for motor control. Passing by pyramidal decussation, some of the fibers continues ventrally, forming the corticospinal tract anterior or medial, and the remaining crosses to form the corticospinal tract side $^{5}$. There is not a consensus in the literature about what percentage of fibers that does not cross, it is cited about 10 to $20 \%$, and some authors suggest that part of that percentage does not cross at the pyramidal decussation, but crosses to reach the segment end. Thus, unlike the majority of studies have reported the involvement of a neurological injury is not exclusively in the contralateral side of lesion; the hemiplegia is installed contralateral to the brain damage, but the ipsilateral side to the lesion is also, in less proportion, affected ${ }^{6-8}$.

Sunnerhagen et al. ${ }^{9}$ relates in his study that more sensitive tests for hemiplegic patients are needed to detect changes in muscle function in the half-body without motor symptoms and the unaffected side should not be considered normal. The lower performance observed in the experiment on the side ipsilateral to the lesion could be the result of both lack of training on the unaffected hemisphere, or the fact that approximately $10 \%$ of descending motor pathways do not cross to the other side 9 . This explanation is supported by the results of Sinkjaer and Magnusson who found that the stiffness of the ankle reflex on the unaffected side was different from healthy subjects. In the clinical rehabilitation, the reduced performance of the unaffected limb should be considered to train functional procedures involving both extremities ${ }^{10}$.

This study aimed to analyze the non-plegic side of hemiplegic individuals by surface electromyography, compared to the same movement in the dominant limb of normal subjects, in order to verify functional changes in the non-affected member.

\section{METHOD}

The focus of this study was the electromyographic analysis (EMG) of flexor and extensor carpi ulnaris for determining the degree of muscle activation during active movements of wrist flexion and extension. In both movements were evaluated both the agonist and the antagonist, to allow the calculation of the agonist-antagonist relationship.

\section{Subjects}

It was evaluated 37 individuals, divided into two groups: [i] hemiplegic group: 22 post-stroke hemiplegic patients - referred by physicians with a diagnosis of unilateral ischemic stroke with no other associated diseases - with $11.6 \pm 9$ years of injury in mean, age of $64.2 \pm 11.7$ years old, 16 males and 6 females individuals, 15 with right hemiplegia and 7 left; in this group the assessment was done in the non-plegic side and only individuals with spasticity degrees 0 to 2 in the Ashworth scale were evaluated, because the individuals with 3 and 4 degrees do not present range of movement; [ii] control group: 15 clinically healthy individuals, with no history of neurological disease, mean age (60.1 \pm 9.5 years old) similar to that of hemiplegic and able to obey simple commands, 8 males and 7 females, all with right-side dominant, which was evaluated. The individuals assessed prior have signed an informed consent form after receiving information about their participation in the study and the ethical implications involving the procedures proposed were approved by the Committee of Ethics in Research of FCT/UNESP $(061 / 2005)$.

\section{Instrumentation}

For this experiment execution a support of PVC with wooden base was confectioned to locate the forearm in neutral position of prono-supination, in order to prevent interference with the instruments of measurement used and to allow that the wrist movements of flexion and extension occurred freely. And an electrogoniometer constituted by a linear potentiometer of precision of $10 \mathrm{KW}$ that registers the angular position of the wrist articulation was developed and confectioned.

Signals were captured using 2 pairs of surface Ag/ $\mathrm{AgCl}$ electrodes (Meditrace model of $3 \mathrm{M}$ ), $10 \mathrm{~mm}$ in diameter. The electrodes had been located in parallel, separated between themselves for $20 \mathrm{~mm}$. In the handle of the electrode is present a preamplifier circuit with gain of 20 times, CMRR (Common Mode Rejection Ratio) bigger than $80 \mathrm{~dB}$ and impedance of $1012 \mathrm{~W}$.

All the signals had been caught in a conditioning signals module of Lynx, model EMG 1000. In this module a canal is configured to receive the signals from electrogoniometer and others two to receive the signals from EMG, presenting a digital filter type Butterworth, lowpass with frequency of $500 \mathrm{~Hz}$ and a high-pass with cut frequency of $20 \mathrm{~Hz}$ and final gain of 1000 times. All the 
canals present frequency of sampling of $2000 \mathrm{~Hz}$. The acquisition and storage of the signals in archives of data had been made by software Bioinspector 1.8 (Lynx $\left.x^{\circ}\right)$.

As it doesn't have in literature standardization of the positioning of the electrodes in forearm, the position was determined by the localization of motor points in the flexor and extensor carpi ulnaris muscles using an electro stimulator and an electrode type "pen". After the localization the electrodes had been located approximately $4 \mathrm{~cm}$ below of the point, prioritizing the region of the muscular womb.

\section{Protocol}

With the forearm in neutral position of prono-supination, the individual executed the movement of wrist extension and after that, the wrist flexion, with the non-plegic limb; and the individuals of the control group with the dominant side. Each movement was repeated ten times, in order to get an adequate amostral number.

\section{Data processing and analysis}

Extracted EMG signals of each cycle had been submitted to a digital filter band- pass type Butterworth, with order 4 and cut frequency of 20 and $500 \mathrm{~Hz}$. After the filtering, it was gotten the linear wrap of the signal. The wraps gotten in the 10 cycles of extension and flexion had been normalized in the time and the amplitude. For the normalization in the amplitude the value of the average of the signal was used; and in the time, the interpolation of data by cubical splines. After the normalization it was gotten an average tracing of EMG signal of each muscle, for the 10 cycles of each movement. The IEMG (integral of electromyography signal) was tabulated and expressed in u.n. (normalized unit).

Initially, an exploratory analysis of the data through the application of descriptive statisticians was achieved to verify the profiles of the groups in study. After this, statistical tests were applied in order to verify differences between the groups ( $\mathrm{p}$-value $<0.05$ ). For comparisons that the distributions of the groups were normal, the $t$-student for unpaired samples was applied, however for those populations that the distribution was not Gaussian (determined by the normality test of Kolmogorov-Smirnov), Mann-Whitney Rank Sum Test was used.

\section{RESULTS}

Data were compared in two moments: flexion and extension. For it movement it was calculated the difference between the muscles and the agonist-antagonist relationship. The Table shows all the results and the statistical differences. For the comparisons with significantly difference, the graphs were plotted and are illustrated in Fig 1 and 2.

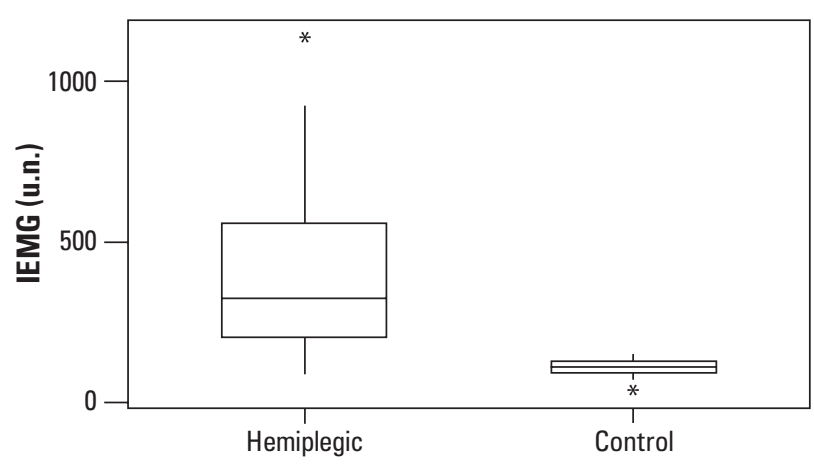

Fig 1. Comparison between flexor muscles (agonists) of hemiplegic and normal individuals during the wrist flexion.

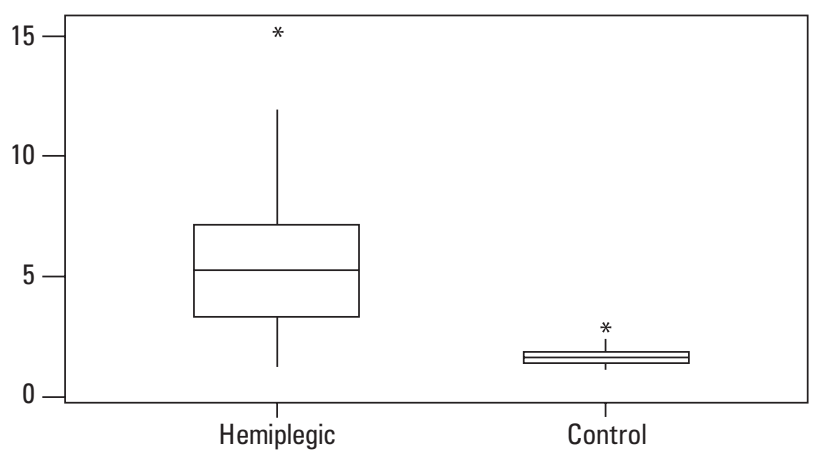

Fig 2. Comparison between agonist-antagonists relationship of hemiplegic and normal individuals during the wrist flexion.

Table. Values of mean and standard deviation (mean \pm SD, in u.n.) of evaluated muscles and agonist-antagonist relationships in the wrist flexion and extension movements separated into the groups (hemiplegic: non-plegic side evaluated; and control: dominant side evaluated).

\begin{tabular}{llccc}
\hline Movement & Muscle & Hemiplegic & Control & p-value \\
\hline Flexion & Flexor & $418.6 \pm 290.7^{*}$ & $106.3 \pm 26.8^{*}$ & $<0.0001$ \\
& Extensor & $71.6 \pm 22.1$ & $64.2 \pm 14.9$ & 0.26 \\
& Agonist-antagonist relationship & $5.8 \pm 3.5^{*}$ & $1.6 \pm 0.4^{*}$ & $<0.0001$ \\
\multirow{2}{*}{ Extension } & Flexor & $77.3 \pm 21.7$ & $85.8 \pm 22.7$ & 0.25 \\
& Extensor & $106.1 \pm 19.1$ & $110.6 \pm 19.4$ & 0.45 \\
& Agonist-antagonist relationship & $1.4 \pm 0.4$ & $1.3 \pm 0.2$ & 0.45 \\
\hline
\end{tabular}

*Refers to statistical significantly differences 


\section{Flexion}

The comparisons between the muscles revealed that the agonists (flexor) are much more activated in the hemiplegic patients (418.6 \pm 290.7 u.n.) when compared to clinically healthy individuals $(106.3 \pm 26.8)$, the statistic test applied in this case was Mann-Whitney that showed significance between the groups $(\mathrm{p}<0.0001)$. This comparison is illustrated in the Fig 1 . When the compared muscles were the antagonists (extensor), the difference were not significantly $(\mathrm{p}=0.26)$ by the $\mathrm{t}$-student test; the hemiplegic group achieved $71.6 \pm 22.1$ u.n. and the control group 64.2 \pm 14.9 . Consequently, when applied Mann-Whitney test, the agonist-antagonist relationship was significantly different too $(\mathrm{p}<0.0001)$, the relation was $5.8 \pm 3.5$ for hemiplegics and 1.6 \pm 0.4 for control group (Fig 2).

\section{Extension}

In this movement, the difference was not significantly for any comparison. In relation to the agonists muscles, the extensor of hemiplegic groups demonstrated an activation of $106.1 \pm 19.1$ u.n. and for the control group the activation was $110.6 \pm 19.4(\mathrm{p}=0.45)$. The antagonists (flexor) showed an activation of $77.3 \pm 21.7$ in the hemiplegic and $85.8 \pm 22.7$ in the control ( $\mathrm{p}=0.25)$. For these two comparisons it was used t-student test. For agonist-antagonist relationship, it was used the Mann-Whitney test and the difference was not significantly too $(\mathrm{p}=0.45)$, the relation was $1.4 \pm 0.4$ for hemiplegic and $1.3 \pm 0.2$ for control.

\section{DISCUSSION}

During the wrist flexion, it was observed an important difference of the non-plegic side of hemiplegics in relation to the clinically healthy individuals; while the individuals of control group presented a mean activation of 106.3 u.n. in the flexor ulnaris, the hemiplegic individuals presented, in their normal side, a mean of 464.6 u.n. during the same movement, resulting in a p-value $<0.0001$. In the antagonist muscles (extensor carpi ulnaris), it was not observed a significant difference. So, the agonist-antagonist relationship during the wrist flexion have presented significant difference between the groups; while in hemiplegic the mean relationship was 6.7, in control group it was 1.7 (p-value $<0.0001$ ). During the extension movement, there was no statistic difference between the evaluated groups.

These founds suggest that there is alteration in coordination and muscular compensation in the limb not affected by the stroke, showing that the non-plegic side of the hemiplegic individuals evaluated neither present the normal pattern found in the control group. It suggests that the central control of the motor units perhaps may be impaired, what contradicts a premise of some authors, that the motor units of the non-plegic limbs of subjects with hemiplegia were essentially normals ${ }^{11}$.
Mirbagueri et al. ${ }^{12}$ when studied the mechanical properties of upper and lower extremities of hemiplegic have observed changes similar to these. The hemiplegic individuals had intrinsic and reflex stiffness in the extremities less affected by stroke, larger than the control subjects. One possible explanation comes from the hyperexcitability of stretch reflexes in the non-paretic members and to the fact that the paths of the monoaminergic system are distributed bilaterally, and its activity may be increased due to stroke. Soon the corticospinal fibers that do not cross may have an increase in activity by altering the excitability of ipsilateral motoneurons. This physiological explanation may be the key for understand the altered patterns of activation found in our study.

Yarosh, Hoffman and Stric ${ }^{13}$ in their study of surface electromyography of the extensor and flexor carpi during movement of the wrist found results similar to ours. Patients with upper limb hemiparesis resultant of a unilateral stroke had deficits in the ability to move the ipsilateral wrist. The deficits were of dominant and non-dominant hemispheres injured: the ipsilateral wrist movements were less uncoordinated than the contralateral, but presented deficit in coordination to reach a target, were weaker and slower than the healthy control subjects studied.

In a previous study conducted by our group, when compared plegic and non-plegic sides of hemiplegic individuals, it was showed that during wrist flexion there is a significantly lower activation of flexors in the plegic side. And for the extensor muscles there were no difference in relation to the control group, both for flexion and the exten$\operatorname{sion}^{14}$. It is known that in the stroke there is a preference of the spasticity for the flexor muscles in the upper limbs and extensor in the lower limbs ${ }^{15-17}$, what may explain why, apparently by the results, the stroke did not affect the pattern of neuro-motor activation of the extensor carpi ulnaris.

Ponten et al. ${ }^{18}$ in a study about morphologyc properties of carpi flexor and extensor muscles in children with cerebral palsy, questioned why the flexor muscles are more strong as a group, suggested that may be possible that the hyperactivity of the nervous system simply activates both flexors and extensors. The flexors overlap the extensors, causing the wrist flexion, because the moment arm of the flexor is larger than the extensor moment arm wrist in flexion, the flexor muscles have the appearance of being stronger.

Barela and Almeida ${ }^{19}$ compared the non-plegic side of individuals with hemiplegic spastic cerebral palsy with the dominant side of normal subjects in flexion of the shoulder and elbow. The results showed that the non-plegic side cannot be considered normal or intact, since the movements in the more distal were managed differently from the proximal portions, which did not occur with normal subjects.

In other study, it was compared parameters related to torque in four isometric exercises with hemiplegia. It 
reported that the apparent weakness of the less affected limb by the stroke might be due to: lower percentage of the descending cortical tract fibers that are originated in the injured local and remains ipsilateral; or more generally, due to a sedentary lifestyle of hemiplegics, which may not be able to maintain the same force exerted by a nondominant arm of a healthy person ${ }^{20}$.

Our results are added to a crescent group in literature that demonstrates the ipsilateral limb "non-affected" does not work normally after a unilateral stroke of brain motor $\operatorname{areas}^{21-23}$. Even with these studies pointing to the differences inconsistencies are showed when we visualize the techniques used in the rehabilitation clinic of upper limbs of hemiplegics patients. One is the training of bilateral movements. This applies neurological postulates of motor coordination inter-members to activate motor synergies between members. Specifically, voluntary movements of the intact limb can facilitate voluntary movements in the paretic member. This activates the primary motor cortex and supplementary motor area for the member intact to increase the probability of voluntary muscle contraction (i.e. motor synergies) in the affected limb when symmetrical movements are executed ${ }^{24}$.

The possible neural mechanisms underlying the bilateral movements are numerous. A basic assumption of the use of bilateral movement is that the therapy of bilateral symmetrical movements activate similar neural networks in both hemispheres when homologous muscle groups are activated simultaneously. Bilateral symmetrical movements, therefore, may allow the activation of the uninjured hemisphere to increase the activation of the injured hemisphere and facilitate control of plegic limb movements promoting neural plasticity.

When evaluated the reorganization of central nervous system with magnetic resonance functional during the therapy of bilateral symmetrical movements, the non-paretic hand's movement have increased the activation of the uninjured hemisphere ${ }^{25}$. The bilateral training lead to an increased recruitment of sensory-motors areas of the contralateral hemisphere and the ipsilateral cerebelum. This recruitment is frequently explained due to the existence of cortico-spinal fibers that do not cross in the pyramidal decussation and are latent in healthy people. Its functional relevance is not yet clear. In patients with motor deficiency after stroke, the rehabilitation with specific bilateral repetitive therapy of upper extremity appears to induce the reorganization in the neural networks contralateral to the lesion, in brain hemisphere and cerebellum, and can operates by recruitment of these brain areas in order to supply functional benefits ${ }^{24}$.

The literature in this area - studying motor control, especially in upper extremities - is still scarce. There are a little amount of researches looking for difference in the non- plegic side; in order to understand exactly what occurs in terms of motor control, more studies should be conducted. This study contributes to understand that the non-plegic side is not normal when compared with a control group, so it should be considered that although the patients have diagnostic of unilateral stroke, we can not ignore that there may be a microdamage contralateral to the plegia not observed on imaging studies, which may explain in part the observed changes in the electromyography spectrum.

\section{REFERENCES}

1. Chae J, Hart R. Intramuscular hand neuroprosthesis for chronic stroke survivors. Neurorehabil Neural Repair 2003;17:109-117.

2. Chae J, Yang G, Park BK, Labatia I. Muscle weakness and co-contraction in upper limb hemiparesis: relationship to motor impairment and physical disability. Neurorehabil Neural Repair 2002;16:241-248.

3. Thrasher TA, Zivanovic V, Mcllroy W, Popovic MR. Rehabilitation of reaching and grasping function in severe hemiplegic patients using functional electrical stimulation therapy. Neurorehabil Neural Repair 2008;22:706-714.

4. Jankowska E, Edgley SA. How can corticospinal tract neurons contribute to ipsilateral movements? A question with implications for recovery of motor functions. Neuroscientist 2006;12:67-79.

5. Machado ABM. Neuroanatomia funcional. São Paulo: Atheneu, 1993.

6. Lent R. Cem bilhões de neurônios: conceitos fundamentais de neurociências. São Paulo: Atheneu, 2004.

7. Brodal A. Anatomia neurológica com correlações clínicas. São Paulo: Rocca, 1984.

8. Lundy-Ekman L. Neurociência: fundamentos para a reabilitação. Rio de Janeiro: Guanabara Koogan, 2000.

9. Sunnerhagen KS, Svantesson U, Lonn L, Krotkiewski M, Grimby G. Upper motor neuron lesions: their effect on muscle performance and appearance in stroke patients with minor. Arch Phys Med Rehabil 1999;80:155-161.

10. Sinkjaer T, Magnusson I. Passive, intrinsic and reflex-mediated stiffness in the ankle extensors of hemiparetic patients. Brain 1994;117:355-363.

11. Tang A, Rymer WZ. Abnormal force: EMG relations in paretic limbs of hemiparetic humans subjects. J Neurol Neurosurg Psychiatry 1981;44:690-698.

12. Mirbagheri MM, Alibiglou L, Thajchayapong M, Rymer,WZ. Muscle and reflex changes with varying joint angle in hemiparetic stroke. J Neuroeng Rehab 2008;98:629-637.

13. Yarosh CA, Hoffman DS, Strick PL .Deficits in movements of wrist ipsilateral to a stroke in hemiparetic subjects. J Neurophsiol 2004;92:3276-3285.

14. Kuriki HU, Azevedo FM, Filho RFN, Alves N, Carvalho AC. Comparative analysis of electromyography pattern in the forearm muscles of hemiplegic patients. Electromyogr Clin Neurophsysiol 2008;48:367-372.

15. Bobath B. Hemiplegia no adulto: avaliação e tratamento. São Paulo: Manole, 1978.

16. Cook AS, Woollacott MH Controle motor: teoria e aplicações práticas. São Paulo: Manole, 2003

17. Hu XL, Tong KY, Song R, et al. Quantitative evaluation of motor functional recovery process in chronic stroke patients during robot-assisted wrist training. J Electromyogr Kinesiol 2008;19:639-650.

18. Ponten E, Frindén J, Thornell L, Lieber, R L.Spastic wrist flexors are more severely affected than wrist extensors in children with cerebral palsy. Dev Med Child Neurol 2005;47:384-389.

19. Barela AMF, Almeida GL. Controle de movimentos voluntários no membro superior não plégico de portadores de paralisia cerebral hemiplégica espástica. Rev Bras Fisioterapia 2006;10:325-332.

20. Mc Crea PH, Eng JJ, Hodgson AJ. Time and magnitude of torque generations is impaired in both arms following stroke. Muscle Nerve 2003;28:46-53.

21. Carey JR, Baxter TL, Di Fabio RP. Tracking control in the nonparetic hand of subjects with stroke. Arch Phsys Med Rehabil 1998;79:435-441.

22. Desrosiers J, Bourbonnais D, Bravo G, Roy P-M, Guay M. Performance of the "unaffected" upper extremity of elderly stroke patients. Stroke 1996:27:1564-1570.

23. Winstein CJ, Pohl PS. Effects of unilateral brain damage on the control of goal-directed hand movements. Exp Brain Res 1995;105:163-174.

24. Stewart KC, Cauraugh JH, Summers JJ. Bilateral movement training and stroke rehabilitation: a systematic review and meta-analysis. J Neurol Sci 2006:244:89-95

25. Luft AR, McCombe-Waller S, Whitall J, et al. Repetitive Bilateral arm training and motor cortex activation in chronic stroke. JAMA 2004;292:1853-1861. 